\title{
Interventions to Improve Access to Medicine in Developing Countries: Mapping WHO's Building Blocks and Supply Chain Functions
}

\author{
Pamela Steele $^{1 *}$, Lakshmy Subramanian ${ }^{2}$ and Foyeke Tolani ${ }^{1}$ \\ ${ }^{1}$ Pamela Steele Associate Ltd, UK \\ ${ }^{2}$ Cranfield University and Pamela Steele Associates Ltd, UK \\ *Corresponding Author: Pamela Steele, Pamela Steele Associate Ltd, UK.
}

Received: June 06, 2019; Published: June 21, 2019

DOI: $10.31080 /$ ASPS.2019.03.0323

\begin{abstract}
Access to medicine remains poor and inequitable in many low- and middle-income countries (LMICs). This is a complex and multi-dimensional issue calling for holistic solutions. Studies in this area focus on singular disciplines, highlighting one or two main issues; this paper seeks to consider this issue from a multi-disciplinary perspective. It first enumerates the supply chain bottlenecks which lead to poor access to medicine. Since access is dependent on a host of factors, it is critical to understand each of these in the context of LMICs. Secondly, the paper proposes interventions to improve access by focusing on availability, affordability, quality and obtainability of medicine. These interventions are categorised into broader areas of focus to help stakeholders understand their role and responsibilities across the supply chain functions. Finally, the paper establishes a rationale for each intervention, matching it to a WHO Building Block and the corresponding supply chain management function. The resulting map will allow stakeholders to envision policies that will contribute to comprehensive solutions that strengthen the public health supply chains in LMICs.

Keywords: Access to Medicine; Supply Chain; Interventions; WHO Building Blocks
\end{abstract}

\section{Abbreviations}

LMIC: Low- and Middle-Income Countries; WHO: World Health Organisation; OECD:Organisation for Economic Co-operation and Development; NCD: Non-Communicable Diseases; IFPMA: International Federation of Pharmaceutical Manufacturers and Associations; MDG: Millennium Development Goals; GFTAM:Global Fund to Fight AIDS, Tuberculosis and Malaria; AMREF: The African Medical and Research Foundation; SCM: Supply Chain Management; R \& D: Research and Development; CEWG: Consultative Expert Working Group; GRO: Grassroots Organisations.

\section{Introduction}

Most low- and middle-income countries lag behind in providing healthcare to their populace, in spite of the Health for All by 2000 initiative [1]. The difficulties in providing good quality healthcare have been a cause of concern, as maintaining the quality of medicine and guaranteeing the availability of health commodities at affordable prices depends on a host of factors that need to be synchronised and integrated for the system to be efficient. In most of these countries, the existing health system (both public and private) is far from being satisfactory, the availability of basic medicine is inadequate, and it is expensive. Improving access to medicine is dependent upon a host of factors and the involvement of a variety of participants.
The growth in development aid has slowed since 2011 by nearly 3 per cent due to donor fatigue and this is a worrying factor for LMICs who rely on donor funds to improve healthcare facilities [2]. Government health expenditure, as a percentage of GDP, has been declining in LMICs, leaving professionals to do more on fewer resources [3]. The declining investment and expenditure have driven the poor away from the public health system. The credibility and effectiveness of health systems are linked is reflected on the patient's ability to obtain the right medication, at the right time, and at the right cost. A medical diagnosis is effective only when it is supported by accessibility to the required medication. This becomes a benchmark for the quality of healthcare and can act as an impetus for improving universal healthcare coverage.

In 2015, the UN agreed that Sustainable Development Goals will include targets such as the elimination of major disease epidemics and the reduction of the burden of childhood obesity. The progress in global health is not inevitable and requires consistent efforts by countries, donors, policymakers, supply chain participants, etc. In 2017 , the improvements in global mortality rates were less pronounced than in the previous decade, and non-communicable diseases (NCDs), for example, accounted for $73.4 \%$ of deaths, an increase of $22.7 \%$ since 2007 [4]. This was attributed to changing diets, urbanisation, and sedentary lifestyles. Moreover, inappropriate and overuse of medication coupled with wastage of resources 
created a gap between the demand and supply that will ultimately lead to a loss of social protection for the poor [5].

In addition, new public health challenges are putting further pressure on already strained health systems and contributing to a high volume of out-of-pocket expenses in LMICs. These challenges include supply chain impediments coupled with legislative and economic transitions taking place in different countries. The various stakeholders including the scientific research community, local governments, public health and regulatory agencies, overseas development agencies, philanthropists, multi-lateral agencies and the non-profit sector's specific duties will contribute to the improvement of healthcare coverage.

In many respects, the cornerstones of public health growth are the pharmaceutical companies who should aim to ensure that medicine is available and accessible, irrespective of socio-economic considerations. These companies have the power to improve supply chains and save lives by providing better access to medicine at affordable prices. Through purposeful collaborations, the said companies can respond to the changing disease patterns, introduce new products and technologies, and promote sustainable, longterm access to medicine.

Emerging economies accounted for $23 \%$ of global spending on pharmaceuticals in 2015 and they are expected to account for $25 \%$ by 2020 [6]. Since exact predictions of diseases and outbreaks are not always possible, a collaborative approach between the public and private sector to develop, support and implement innovative practice is of utmost importance. The ideal solution to these challenges would be to introduce free provision of medicine to patients with low costs for governments. This would help to improve health benefits and decrease out-of-pocket expenditures. However, in spite of the attempts to support this approach, not much progress has been witnessed in LMICs [7].

\section{Literature Review}

Since the adoption of the Millennium Development Goals (MDG) in 2000 and the establishment of the Global Fund to Fight AIDS, Tuberculosis and Malaria (GFTAM) in 2002, there has been an increase in financial donations from multilateral and bilateral donors to LMICs $[8,9]$, resulting in an exponential increase in the procurement of medical products. But the success of health programmes is not only dependent on the availability of funds to finance the procurement of medicine; if these medicines are inaccessible to the patients who require them, suffering and premature mortality will persist. Issues with access to medicine remain one of the leading causes of preventable deaths and poor health outcomes in LMICs.

Public health supply chains carry the responsibility of improving the health outcomes by addressing inaccessibility, which can put an additional strain on the already struggling complex public health supply chain. Despite increased donor funding and an ar- ray of new products (including vaccines and essential medicine), there are factors that continue to restrict access to health products. Namely, the capacity of a country's supply chain to select, forecast, procure, and deliver health supplies is a major hinderance [10]. There is an urgent need for more research into public health supply chains in LMICs if any improvement in the access to medicine is to be made.

\section{Supply chains and the corresponding management}

Van Wassenhove [11], outlines three types of flows supported by a supply chain that require careful design and close coordination. Those include material flows, the physical product flows from suppliers to customers, including reverse flows for product returns, servicing, and recycling; information flows, such as order transmission and order tracking, which coordinate the material flows; and financial flows-credit terms, payment schedules, and consignment arrangements. Closely related to 'supply chain' is 'supply chain management' (SCM). To some, SCM is the coordination of the supply chain activities [12]. Others provide similar definitions but refer to 'business functions' rather than 'activities,' reflecting their view of the supply chain as a network of entities [13].

\section{Health systems}

The World Health Organization (WHO) defines a health system as 'all the activities whose primary purpose is to promote, restore or maintain health' [14]. The WHO 2007 framework for health systems is widely recognised, and its broad approach is the most suitable for identifying the range of issues that might affect the availability of medicine. It consists of six interconnected building blocks, required for an effective health system, namely, service delivery, health workforce, information, medical products, vaccines and technology, financing, and leadership and governance. According to Shakarishvili et al. [15], this approach is 'a useful means for locating, describing, and classifying health system constraints, for identifying where and why investments are needed, what will happen as a result, and by what means the change can be monitored' [15].

Building on the literature review, this paper examines and assesses the strategies for improving the accessibility of medicine LMICs. The paper highlights supply chain challenges throughout the process and the resultant effect on health systems. This paper recommends areas for holistic improvement. The paper will help to disseminate information and shorten the learning curve of all the stakeholders involved in trying to improve the health outcomes of any developing nation. The paper is structured as follows: Section 2 discusses the supply chain bottlenecks in achieving better medicine accessibility; Section 3 highlights interventions to increase healthcare coverage through improved access to medicine; Section 4 matches the interventions to WHO building blocks and supply chain management; and Section 5 concludes the paper 
Supply chain bottlenecks in achieving better medicine accessibility

The methods of procurement and distribution of medicine can vary across countries. However, supply chain issues and disruptions can interrupt the availability of medicine at the lower echelons of the population. Procurement delays can hamper the patients' confidence in public health systems and defeat the basic purpose of public health supply chain. Delays can emerge due to supplier mismanagement, delayed tendering, customs issues, poor specifications and many more. Moreover, each country has its unique set of challenges which cannot be solved through generalised solutions. Therefore, understanding contextualised factors and avoiding noncustomised approaches is a step towards better health outcomes.
Capacity planning and development is crucial throughout the supply chain functions [16]. LMICs often face skill-gaps which contributes to the fragmentation and inefficiency of public health systems. There continues to be a dire need for training and capacity development of existing staff [17]. The employment of procurement staff without the right qualifications and training further jeopardises the procurement system. Employees become vulnerable to audit and vigilance issues, leading to defensive office procedures. Furthermore, the distribution of medicine, in terms of last-mile delivery, can pose various challenges due to insufficient infrastructure and lack of legislative support.

The following table highlights the key supply chain challenges and the solutions required to overcome them in an LMIC context. Besides the challenges mentioned in Table 1, inherent systemic

\begin{tabular}{|c|c|c|}
\hline $\begin{array}{l}\text { Supply chain } \\
\text { functions }\end{array}$ & Challenges & Requirements \\
\hline $\begin{array}{l}\text { Selection of } \\
\text { medicine }\end{array}$ & $\begin{array}{l}\text { - Poor selection of essential medicine } \\
\text { - Lack of standard practice } \\
\text { - Lack of transparency } \\
\text { - Low human capacity to carry on this function }\end{array}$ & $\begin{array}{l}\text { - Proper understanding of the Essential Medicine List } \\
\text { - Linking requirements to disease pattern of the country } \\
\text { through proper data collection and feedback system }\end{array}$ \\
\hline Quantification & $\begin{array}{l}\text { - Inadequate and less-reliable data on consumption } \\
\text { - Poor quantification and forecasting skills }\end{array}$ & $\begin{array}{l}\text { - Evidence-based decisions } \\
\text { - Ability to forecast built on need and patient demand }\end{array}$ \\
\hline Procurement & $\begin{array}{l}\text { - Unclear procedures } \\
\text { - Procedural delays due to poor quantification } \\
\text { - Use of low/outdated technology } \\
\text { - Supplier uncertainty }\end{array}$ & $\begin{array}{l}\text { - Matching of procurement to the Essential Medicine List } \\
\text { - Use of technology to reduce lead times and expedite pro- } \\
\text { curement cycle } \\
\text { - Better supplier selection and management }\end{array}$ \\
\hline $\begin{array}{l}\text { Quali } \\
\text { medi }\end{array}$ & $\begin{array}{l}\text { - Counterfeit drugs crowding the public health sys- } \\
\text { tems } \\
\text { - Treatment failures extending illness, adverse reac- } \\
\text { tions, disability and death (IFPMA) } \\
\text { - Detection is also difficult as the supply chain uti- } \\
\text { lizes complex international trade routes, within } \\
\text { a system where police, customs, and drug regula- } \\
\text { tors are not unified (WHO) }\end{array}$ & $\begin{array}{l}\text { - Strict quality checks and adherence to criteria } \\
\text { - Blacklisting of suppliers for substandard/spurious medi- } \\
\text { cine } \\
\text { - Sample testing at delivery points and along the supply } \\
\text { chain by independent accredited laboratories. } \\
\text { - Use of modern technology }\end{array}$ \\
\hline $\begin{array}{l}\text { Inve } \\
\text { man }\end{array}$ & $\begin{array}{l}\text { - Mismatch between demand and supply } \\
\text { - Inadequate methods of inventory control leading } \\
\text { to overstocking/understocking } \\
\text { - Lack of human capacity }\end{array}$ & $\begin{array}{l}\text { - Inventory decisions based on consumption data } \\
\text { - Real-time inventory data shared across the public health } \\
\text { supply chains for better replenishment and distribution } \\
\text { strategies. }\end{array}$ \\
\hline Warehousing & $\begin{array}{l}\text { - Poor conditions of storage facilities } \\
\text { - Lack of adequate infrastructure (temperature con- } \\
\text { trol) } \\
\text { - Low utilisation of technology } \\
\text { - Reduced security and human capacity }\end{array}$ & $\begin{array}{l}\text { - Adoption of a warehouse management system } \\
\text { - Modern infrastructure for fast order processing, such as } \\
\text { racking and mechanical handling equipment (MHE) } \\
\text { - Well-trained and skilled staff for warehouse operations; } \\
\text { storage and security. }\end{array}$ \\
\hline Distribution & $\begin{array}{l}\text { - Low availability of good quality public transport } \\
\text { and very expensive private fleet } \\
\text { - Low frequency of distribution to lower tiers and } \\
\text { rural areas } \\
\text { - Last-mile delivery failure due to inaccessible loca- } \\
\text { tions and transportation constraints } \\
\text { - Poor coordination between the central warehous- } \\
\text { es and health facilities }\end{array}$ & $\begin{array}{l}\text { - Using modern fleet management technology to improve } \\
\text { distribution } \\
\text { - Embracing GPS enabled last mile delivery for better health } \\
\text { outcomes } \\
\text { - Outsourcing, depending on the health commodities and } \\
\text { the regions to be delivered. }\end{array}$ \\
\hline $\begin{array}{l}\text { Support } \\
\text { functions }\end{array}$ & $\begin{array}{l}\text { - } \quad \text { Poor funding } \\
\text { - } \quad \text { Low human capacity } \\
\text { - } \quad \text { Poor vendor procedures } \\
\end{array}$ & $\begin{array}{l}\text { - Capacity development through workforce engagement } \\
\text { and motivation } \\
\text { - Performance management tools to instil better feedback } \\
\text { and structure } \\
\text { - Improved relationship management supporting long- } \\
\text { term alliances and support }\end{array}$ \\
\hline
\end{tabular}

Table 1: Supply chain challenges and requirements to be met to improve the availability of medicine in LMICs. 
problems of governance, poor political support, ineffective leadership and constant reshuffling of key positions when trying to push for reforms could continue to hamper the process.

Interventions to increase healthcare coverage through improved access to medicine

The various supply chain challenges highlighted in Table 1 have a negative impact on the availability and accessibility of medicine at the last mile. Moreover, another reason for supply chain interruptions could be the diverse geographical topographies ranging from plains to difficult-to-access mountainous areas. Public health chains can become more effective through interventions to improve access to medicine focused on better availability, affordability, quality and obtainability. The interventions will result in tools to increase healthcare coverage and achieve better health outcomes. They will also act as solutions to the various supply chain bottlenecks that cannot be solved in isolation $[18,19]$.

\section{Improving the availability of medicine}

It is discouraging to realise that an overwhelming majority of medicine is designed for the needs of high-income countries. This results from a lack of incentives for research and development of medicine for the needs of LMICs. Pharmaceutical companies operate in a system influenced by the profits, where the consumers 'choose' from the portfolio of drugs produced through demand [20]. However, the purchasing power is very low or non-existent in LMICs. Again, lack of funds results in high out-of-pocket expenditure that represents a similarly high proportion of the population's income. The lack of health insurances aggravates the issue further. Another trend that affects the availability of medicine is the inequality in research and development of medicine. Pharmaceutical companies consider the needs of LMICs only when a specific disease pathway lead to them and forcing the stretch beyond low profit margins [21].

Some of the existing solutions embraced by countries to strengthen research and development to improve the availability of medicine are:

- Grants: Research grants are a common tool to boost research and innovation into this problem. Applications are usually initiated by international donors and agencies. The grants help to cover the initial costs, and they are a step towards improving health outcomes. Yet, such grants create dependency on the donors and their availability can be sporadic.

- Treaties: The implementation of a global research and development (R\&D) treaty was recommended by the WHO Consultative Expert Working Group (CEWG) on Research and Development: Financing and Coordination. The treaty is supported by over 80 health research institutions, product development partnerships, and public interest NGOs [22]. These treaties are crucial for the growth of LMICs [23].

- Market-based commitments: Advance market commitments create an agreement in advance of the development of a product to purchase guaranteed amounts that meet criteria set by the donor (Commission on Intellectual Property Rights, Innovation and Public Health, 2006). Critics have opined that it is difficult to measure the success of these strategies because of the complexity and time involved [24].

- Priority Review Vouchers: These provide incentives for research and development by shortening the review process of future medicine. However, investigation shows that these are not used widely [25].

- Product Development Partnerships: These are initiatives to bring together public, private and funding organisations to provide an impetus for improving the availability of medicine through research and development [25]. This is an opportunity for developing nations to combine the efforts of the various stakeholders and work towards better health coverage. These partnerships try to strike a balance between public and private interests [26].

- Patent Pools: These involve the cross-licensing of intellectual property by participants to increase access to essential technologies for products [26]. These pools act as a uniform platform for licensing of all patents and make the process of drug discovery more efficient. However, it should be noted that use of patent pools for pharmaceutical R\&D is relatively new, and they have not been widely used [27].

However, the above-mentioned initiatives have not yielded many results in LMICs. Therefore, some of the interventions that can be adopted are

- Tradable patent terms can be introduced, meaning that pharmaceutical initiatives serving a humanitarian purpose would receive an extended patent term that can be used with a different pharmaceutical product [28].

- Pharmaceutical companies are urged to begin systematically planning ahead during clinical development to ensure that successful products can be made widely available more quickly in developing countries. They can pioneer voluntary licensing and establish multi-sector capacity development partnerships [29].

- Refocusing the direction of the major stakeholders may be needed to boost meaningful research and development in LMICs. Pharmaceutical companies need to take more responsibility, allocate time and resources to improve healthcare in LMICs [30]. Priorities must span across diseases, conditions and pathogens and the different products needed per disease, such as medicine or diagnostic tools.

- State-run programmes can ease off the pressure from private sector. This will also induce accountability into the public sector for the availability of medicine. 
- Differential pricing can be adopted allowing LMICs to pay for medicine based on their ability and per capita household income.

\section{Improving the affordability of medicine}

The affordability of medicine is the ability of the population to pay for medicine without compromising other essentials, such as housing, education and food. Affordability also depends on who is paying-the patient or another stakeholder in the local healthcare system. In LMICs nearly $70 \%$ of spending on medicine is out-ofpocket. Different countries have different income capacities and these differences should be kept in mind while deciding the prices of medicine. The cost of medicine is usually determined by the cost of manufacturing, supplying, and the research involved. The costs often do not include the opportunity cost and are inflated to reap higher profits. Studies have highlighted that efforts to make medicine more affordable are lacking in LMICs by comparison to developed countries [31], mainly due to lack of funding [32]. LMICs do not have efficient systems for clinical trials, top-level medical schools and experienced clinicians [33] which hinders access to affordable medicine (IFPMA). Again, affordability of medicine is influenced by huge mark-ups resulting in poor healthcare coverage.

Some of the existing tools embraced by countries to improve affordability by reducing the cost of medicine are:

- Differential pricing, which occurs when varying prices are charged by the seller according to the purchasing power of governments and households in different countries [34]. However, it involves a high risk of arbitrage and erosion of high-income markets [35].

- Monopsonies are market structures where the buyer has the control power. In many countries, when public procurement is done by the government, it functions as a monopsony, allowing for the negotiation of lower prices (e.g.: PHARMAC in New Zealand). This kind of a market structure can help to reduce the cost of the medicine, generating better savings and allowing affordable health treatment. On the other hand, this model can suffer from lack of transparency and knowledge, since most contracts are confidential [36].

- Patent law flexibilities can include changing the terms of patents, strengthening patent criteria and introducing competition [37].

As with availability, the previous initiatives have not yielded visible results in LMICs. Therefore, some of the interventions that can be adopted to improve affordability of medicine could be:

- Increased transparency between the pharmaceutical sector and the country government to understand contexualised needs and challenges. Pharmaceutical companies can work with national governments and partners to expand pricing schemes and donation programmes.
- LMICs must have the political will to increase affordability, and the capacity and financing to develop policy and effective systems to that effect.

- Backdoor deals and evergreening need to be stopped completely. Backdoor deals occur when a monopolist incentivises a local company to stay away from the market [38]. Evergreening refers to penetration of secondary patenting of the most successful medicine, which may further reduce the ability of generics to enter the market [39].

- Time-bound targets for new products in LMICs will help to secure market access and grow a strong market share.

- It is necessary to enforce obligations on pharmaceutical firms to ensure that life-saving medicine is provided in LMICs [30]. This can be achieved by prioritising research and development on disease gaps.

- Socio-economic factors are to be frequently considered while setting medicine prices. The factors considered the most relevant are disease burden, healthcare system and financing; and the level of economic and human development. This will help in creating patient access profiles and facilitate better affordability.

- Stakeholders should explore ways of mobilising new and innovative means of financing, developing and increasing resources available for health.

\section{Improving the quality of medicine}

Inferior quality medication and counterfeit products have a negative impact on the health systems of any country, especially of LMICs, where some disease reports indicate that half of the drugs may have few to no active ingredients [40]. Medicine may also contain toxic substances which are harmful for the community. These issues can cause treatment failure, extended illness, adverse reactions, disability and death [41]. Substandard medicine often looks very similar to the original and it is difficult to differentiate them. The lucrative nature of these products often fosters cross-border criminal activities, making detection and prosecution difficult. The counterfeits attract the various stakeholders alike and lack of proper legislation, enforcement and heavy penalties make deterrence very limited [42]. Detection is also made difficult by the spread of supply chains across different countries and continents, meaning that they are not unified in a single system [43]. Another factor that impacts on the quality of medicine is that legally produced generics legally produced may confiscated (en route) on grounds of IP breach even, though the destination country could legally distribute it [44].

Currently, the efficacy of medicine is generally checked, and the desired quality achieved through the following initiatives: 
- Product Authentication uses colour shifting inks, holograms and chemical markers embedded in drugs to identify legiti mate medicines [45].

- E-coding is another method followed by many countries to help identify substandard drugs. For example, China uses an 'e-coding' system whereby each party within the supply chain is required to send a 'signal' to confirm receipt or dispatch to a regulatory database [46].

- Track and trace devices and technology.

- National enforcement of strict sanctions and penalties.

These general measures have not yielded the results LMICs. Therefore, some of the interventions that can be adopted to improve quality of medicine are:

- Educating patients and healthcare workers on the accurate identification and use of the medicine through means that meet a range of needs, including language, literacy and cultural, demographic and environmental needs.

- Creation of international marking systems, so that medicine does not need to be re-marked when entering a new country, saving supply chain costs and lead times.

- Stakeholders should have policies, procedures and resources in place to carry out effective drug recalls to protect the public from a defective or potentially harmful product.

- Sharing of information and communication by identifying emerging markets, particularly, when it comes to the implementation of segmented pricing and product registration filings, and to transferring knowledge, expertise and other capacities to the local manufacture of pharmaceutical products.

- Inclusion of LMICs in international frameworks.

- More research regarding substandard medicine is needed as the prevalence of substandard medicine is still the result of 'informed guesses' [40].

- An international code of practice to aid in coordinating regulatory, customs and law enforcement agencies.

\section{Improving obtainability of medicine}

In public health, the availability of medicine is considered a crucial issue. However, most of the studies overlook obtainability, since it is determined by a host of factors both within and outside the country's control. Obtainability can be influenced by challenges in the country's health system, infrastructure, legal barriers, sociocultural influences, etc. [47]. This leads to patient unawareness and adherence to non-standardised practice. Again, the availability of healthcare personnel per capita is very low in LMICs, reducing the possibility of preventative medicine and diagnosis. Doctors and other healthcare personnel may be concentrated in urban areas, leaving rural populations without easy access to basic healthcare. In rural areas, it may be very time-consuming or expensive to reach the nearest health point or distribution facility [48]. It is also observed that the wholesale market is excessively fragmented with poor traceability [47]. Even, if the medicine makes it to the local community centre, access may be physically restricted due to lack of basic infrastructure.
The existing initiatives to overcome these challenges are:

- Task-shifting is a tool embraced to develop the existing human capacity and provide a more sustainable solution. This process involves the movement of specific tasks from highly qualified workers to those with less training and fewer qualifications, in order to make more efficient use of the available human resources for health [49].

- Interventions through grassroots organisations (GROs), made up of interested parties coming together for self-help (as opposed to interested parties coming together to help others, as tends to happen in the sector) [48].

Once again, these initiatives have not yielded adequate results in LMICs. Some interventions that can be adopted to improve the obtainability of medicine are:

- Acceptance and identification of supply chain issues which are resulting in poor rates of medicine obtainability at the last-mile. This can be achieved through capacity planning and development at the various levels. Initiatives in this area range from training on good distribution practice, proper warehousing, forecasting and cold chain requirements, to projects that use technology to track stock and prevent stockouts.

- Strong political will to support the public health systems and supply chains to overcome bottlenecks by creating more distribution hubs, even in rural areas.

- Tailored mechanisms for change using contexualised and issue-driven technology, avoiding the blind adoption of modern technology without recognition of grassroot realities.

- Aligning global, regional and country-level supply planning processes with demand for the products by making efforts to understand product distribution and demand behaviour in different countries and applying the information for timely supply.

- The socio-economic determinants of health must be recognised in order to define a holistic framework.

Improving access to new medicine

It is critical for all LMICs to have access to new drugs and medicine. This can be done through proper advance planning on the part of the various stakeholders and through a clear understanding of the access plan. Pharmaceutical companies can voluntarily enter licensing agreements under pro-access terms to facilitate generic entry [50]. This can be achieved through planning for and aligning with other actors along supply chains to ensure the timely supply of good quality products and prevent stockouts.

Planning can also be done through submitting products to WHO's prequalification process to allow for UN procurement and accelerate the registration process in countries with weak national regulatory authorities [51]. Access plans can also be implemented through local partners to make the new products widely accessible. Generally, access plans first take the shape of commitments made 
during the early stages of development before being turned into concrete strategies or agreements. This is a necessary first step, and efforts must be made to ensure these commitments are turned into action.

Matching the interventions to WHO building blocks and supply chain functions

It is well-recognised that access to medicine is not only a matter of life and death; it also enhances the quality of life and it is important for overall improved standards of living. Access to medicine is a complex and multi-dimensional issue calling for holistic solutions. Measures must include improving supply chains, understanding social determinants of health, encouraging policy coherence, implementing proactive intellectual property regimes, and ensuring that health delivery systems are appropriate to those they serve. The following table summarises the proposed interventions and their areas of focus. We have identified the following areas of focus:

- Analytical/Scientific: These interventions help in generating new ideas and foster innovations to improve access to medicines.

- Structural: These interventions establish processes, procedures, and platforms to enhance and facilitate activities.

- Collaborative: These interventions enhance co-ordination among the various stakeholders and technical partners.

- Legislative: These interventions aim to bring changes in the legislative frameworks and boost political will.

- Workforce development: These interventions facilitate building the capacity of the workforce.

\begin{tabular}{|c|c|c|c|}
\hline $\begin{array}{l}\text { Access to } \\
\text { medicine }\end{array}$ & Interventions & Area of focus & WHO building block \\
\hline \multirow{5}{*}{$\begin{array}{l}\text { Improve the } \\
\text { availability of } \\
\text { medicine }\end{array}$} & Tradable patent & Analytical/Scientific & Information and Research \\
\hline & $\begin{array}{l}\text { Systematically planning during clinical develop- } \\
\text { ment }\end{array}$ & Structural & Information and Research \\
\hline & $\begin{array}{l}\text { Refocusing of the direction of the Major stake- } \\
\text { holders }\end{array}$ & Collaborative & $\begin{array}{l}\text { Leadership and Governance, Service } \\
\text { delivery }\end{array}$ \\
\hline & State-run programmes & Legislative & $\begin{array}{l}\text { Leadership and Governance, Service } \\
\text { delivery }\end{array}$ \\
\hline & Differential pricing & Structural & Finance \\
\hline \multirow{7}{*}{$\begin{array}{l}\text { Improve } \\
\text { affordability } \\
\text { of medicine }\end{array}$} & $\begin{array}{l}\text { Increased transparency between the pharma- } \\
\text { ceutical sector and the country government }\end{array}$ & Collaborative and Legislative & Leadership and Governance \\
\hline & Political will & Legislative & Leadership and Governance \\
\hline & $\begin{array}{l}\text { Backdoor deals and evergreening need to be } \\
\text { stopped }\end{array}$ & Collaborative and Legislative & Leadership and Governance \\
\hline & $\begin{array}{l}\text { Time-bound targets for filling to register new } \\
\text { products }\end{array}$ & Analytical/Scientific & Information and Research \\
\hline & $\begin{array}{l}\text { Setting priority research and development ac- } \\
\text { count to focus on disease gaps. }\end{array}$ & Analytical/Scientific & Information and Research \\
\hline & $\begin{array}{l}\text { Mobilizing new and innovative means of financ- } \\
\text { ing }\end{array}$ & Structural & Finance \\
\hline & Socio-economic factors & Structural & Leadership and Governance \\
\hline \multirow{6}{*}{$\begin{array}{l}\text { Improving } \\
\text { the quality of } \\
\text { medicine }\end{array}$} & Educating patients and healthcare workers & Workforce development & Health Workforce \\
\hline & International marking systems & Collaborative, legislative & Leadership and governance \\
\hline & Effective drug recalls & Structural & Information and Research \\
\hline & Sharing of information and communication & Collaborative & Information and Research \\
\hline & International frameworks and code of practice & Legislative & $\begin{array}{l}\text { Leadership and governance, Service } \\
\text { delivery }\end{array}$ \\
\hline & Research regarding substandard medicines & Analytical/Scientific & Information and Research \\
\hline \multirow{5}{*}{$\begin{array}{l}\text { Improving } \\
\text { the } \\
\text { obtainability } \\
\text { of medicine }\end{array}$} & Capacity planning and development & Workforce development & Health Workforce \\
\hline & $\begin{array}{l}\text { Strong political will to support the public health } \\
\text { systems and supply chains }\end{array}$ & Legislative, Structural & $\begin{array}{l}\text { Leadership and Governance, Service } \\
\text { delivery }\end{array}$ \\
\hline & Tailored mechanisms for change & Collaborative & Leadership and governance \\
\hline & $\begin{array}{l}\text { Aligning global, regional and country-level sup- } \\
\text { ply planning processes with demand }\end{array}$ & Structural & $\begin{array}{l}\text { Service delivery, Information and Re- } \\
\text { search }\end{array}$ \\
\hline & Socio-economic determinants of health & Structural & $\begin{array}{l}\text { Leadership and Research, Service de- } \\
\text { livery }\end{array}$ \\
\hline
\end{tabular}

Table 2: Proposed interventions and the area of focus in developing nations. 
We also link each intervention to a WHO Building Block (refer to Table 2) and the corresponding supply chain management functions (refer to Table 3). This mapping will support stakeholders get a broader picture and envision policies, which will contribute towards comprehensive solutions to strengthen the public health supply chains in developing nations. Establishing better rationality to decisions and building it on relevant constraints will support developing nations propel towards stronger health systems and public health supply chains.

\begin{tabular}{|l|c|}
\hline $\begin{array}{c}\text { WHO Building } \\
\text { Block }\end{array}$ & \multicolumn{1}{c|}{ Supply chain functions } \\
\hline $\begin{array}{l}\text { Information } \\
\text { and Research }\end{array}$ & $\begin{array}{c}\text { Selection of medicines, quantification, } \\
\text { procurement, inventory management }\end{array}$ \\
\hline $\begin{array}{l}\text { Leadership and } \\
\text { Governance }\end{array}$ & $\begin{array}{r}\text { Policies, co-ordination, transparency, } \\
\text { accountability, change management, } \\
\text { stakeholder management }\end{array}$ \\
\hline Finance & $\begin{array}{c}\text { Funding (Donor and Government), drug } \\
\text { revolving fund, investments }\end{array}$ \\
\hline $\begin{array}{l}\text { Health } \\
\text { Workforce }\end{array}$ & $\begin{array}{r}\text { Staffing, skills, supervision, performance } \\
\text { management, working conditions, motivation, } \\
\text { incentives }\end{array}$ \\
\hline $\begin{array}{l}\text { Service } \\
\text { delivery }\end{array}$ & $\begin{array}{c}\text { Procurement, warehousing, distribution tools, } \\
\text { transportation, technology, last mile delivery }\end{array}$ \\
\hline
\end{tabular}

Table 3: WHO Building Blocks and supply chain functions.

\section{Conclusion}

Access to medicines requires efficient public supply chains where each component of the cycle is aligned with the performance of the other. If one component is not managed correctly, other components are bound to be adversely impacted. With an efficient system in place, procurement, and distribution of appropriate medicine and equipment, rational diagnostic, therapeutic practices can be promoted in LMICs. The integration of strategies into contextualised frameworks will create a sustainable roadmap for better access to medicine. Developing nations are the new frontiers for growth, and hence provide opportunities to improve the quality of human care and innovations. This creates a platform for the various stakeholders to enter, understand, and develop effective policies to have a more positive and significant effect on the majority of the population. Interventions to improve universal healthcare through better access to medicine will benefit LMICs with improved health systems and solutions to local needs. Since the disease patterns and the strength of public health systems differ across countries, tailored interventions which incorporate training for healthcare workers and health financing can help overcome country-specific barriers. Inclusive involvements will aim to include people living on very low incomes to improve access to specific medicine or other health products. This will make a tremendous difference and provide medicine which the poor people cannot afford and at the same time reduce the out-of-pocket expenditure.

\section{Bibliography}

1. Regional Committee for Western Pacific, 032, Global Strategy for Health for All by the Year WHO Regional Office Western Pacific, 1981, Manila, (2000).

2. Dieleman JL., et al. "Development assistance for health: past trends, associations, and the future of international financial flows for health". Lancet 387.10037 (2016): 2536-2544.

3. OECD. "How Much is Too Much? Value for Money in Health Spending”, OECD (2010).

4. GBD 2015 SDG Collaborators SS., et al. "Measuring the healthrelated Sustainable Development Goals in 188 countries: a baseline analysis from the Global Burden of Disease Study 2015". Lancet (London, England). 388.10053 (2016):18131850.

5. Chisholm D and B Evans D. "Improving health system efficiency as a means of moving towards universal coverage". World Health Report Background 28 (2010):1-30.

6. The Pharmaceutical Industry and Global Health (2018).

7. Leive Adam and Xu Ke. "Coping with out-of-pocket health payments: empirical evidence from 15 African countries". Bulletin of the World Health Organization Past 86.11 (2008): 849-856.

8. AMREF. Putting African Communities First: Enhancing Capacity and Participation to Close the Gap Health Systems (2007).

9. Levine R., et al. "Demand Forecasting for Essential Medical Technologies". American Journal of Law and Medicine 34.2-3 (2008): 225-255.

10. Mustaffa NH and Potter A. "Healthcare supply chain management in Malaysia: A case study. Supply Chain Management". An International Journal 14.3 (2009): 234-243.

11. Van Wassenhove LN. "Humanitarian aid logistics: supply chain management in high gear". Journal of the Operational Research Society 57.5 (2005): 475-489.

12. Lummus RR., et al. "The relationship of logistics to supply chain management: developing a common industry definition". Industrial Management and Data Systems 101.8 (2001): 426-432.

13. Mentzer JT., et al. "Defining Supply Chain Management,". Journal of Business Logistics 22.2 (2001): 1-25.

14. Musgrove P., et al. "Health Systems: Improving Performance,". World Health Organisation (2000). 
15. Shakarishvili G., et al. "Building on Health Systems Frameworks for Developing a Common Approach to Health: Draft for Discussion, Prepared for the World Bank, the Global Fund and the GAVI Alliance (2009).

16. Arvis JF., et al. "Connecting to Compete 2018: Trade Logistics in the Global Economy". World Bank (2018).

17. Kress D., et al. "Assessment of Primary Health Care System Performance in Nigeria: Using the Primary Health Care Performance Indicator Conceptual Framework". Health Systems and Reform 2.4 (2016): 302-318.

18. IFPMA The Treat of False Friends: Joining Efforts to Protect Patients Against Online Sales of Fake Medicines (2012).

19. World Health Organization (WHO) Counterfeits FAQ (2009).

20. Vacca R. "Intellectual Property and Public Health - A White Paper". Akron Research School of Law, University of Akron. (2013): 13-11.

21. Pugatch M., et al. "Assembling the Pharmaceutical R\&D Puzzle for Needs in the Developing World. Commissioned by International Federation of Pharmaceutical Manufacturers and Associations. (2012).

22. Balasubramaniam T. "Welcome Trust Tells WHO it Opposes $\mathrm{R}$ and D Treaty and the De-Linkage of R\&D Costs from Drug Prices". Knowledge Ecology International (2012).

23. Gervais D. 'TRIPS \& Development', SAGE Handbook on Intellectual Property. In: David M, and Halbert D (eds). SAGE, London, UK (2013).

24. Cernuschi., et al. "Advance Market Commitment for Pneumococcal Vaccines". Bulletin World Health Organization 89 (2011): 913-918.

25. Sakhia S. "Paladin Receives Priority Review Status from FDA for Impavido: NDA Submission” (2013).

26. Lipkus N. "How to Understand Product Development: PublicPrivate Partnerships as Vehicles for Innovation in Combating Neglected Disease". Michigan State University Journal of Medicine and Law 10 (2006): 385-427.

27. Pugatch M. "Patent Pools and Collaborative Initiatives: Assessing the Efficacy of Alternatives to IP in the Development of New Pharmaceutical Drugs, Especially for Neglected Diseases - An Empirical Analysis". European Journal of Risk Regulation 2.4 (2011): 566-571.

28. Ilg M. "Market Competition in Aid of Humanitarian Concern: Reconsidering Pharmaceutical Drug Patents". Chicago-Kent Journal of Intellectual Property 9 (2010): 149-178.
29. Oomen Karin P Q., et. al. "Improving Access to Cancer Care: A First Analysis of Pharmaceutical Company Actions in Low- and Middle-Income Countries. Amsterdam (2017).

30. Oke EK. "Using the Right to Health to Enforce the Corporate Responsibilities of Pharmaceutical Companies with Regard to Access to Medicines". Journal of Health Diplomacy 1.1 (2013): 1-15.

31. Lanjouw J and MacLeod M. "Pharmaceutical R\&D for LowIncome Countries: Global Trends and Participation by Indian Firms". Economic and Political Weekly 40.39 (2005): 9-17.

32. White-Guay B. "Regulation of Medicines in Low and MiddleIncome Countries: Current Challenges and Future Prospects', in Galambos L and Sturchio J (eds), Addressing the Gaps in Global Policy and Research for Non-Communicable Diseases". Report of the IFPMA Non-Communicable Diseases Working Group (2011): 4-8.

33. International Federation of Pharmaceutical Manufacturers and Associations (IFPMA). The Pharmaceutical Industry and Global Health: Facts and Figures (2012).

34. World Health Organization (WHO) Report of the Workshop on Differential Pricing \& Financing of Essential Drugs (2001).

35. Yadav P. "Differential Pricing for Pharmaceuticals: Review of Current Knowledge, New Findings and Ideas for Action". Study Conducted for the UK Department for International Development (DFID) (2010).

36. Feek C., et al. "Experience with Rationing Health Care in New Zealand”. British Medical Journal 318.7194 (1999): 1346-1348.

37. Gervais D. "Patentability Criteria as TRIPS Flexibilities: The Examples of China and India”, In: Bagley M and Okediji R (eds), Patent Law in a Global Perspective". Oxford University Press, Oxford, UK (2014): 541-569.

38. Kesselheim AS., et al. "Pay for Delay" Settlements of Disputes over Pharmaceutical Patents". The New England Journal of Medicine 365.15 (2011): 1439-1445.

39. Amin T and Kesslheim A. "Secondary Patenting of Branded Pharmaceuticals: A Case Study of How Patents on Two HIV Drugs Could be Extended for Decades". Health Affairs 31.10 (2012): 2286-2294.

40. Attaran A., et al. "How to Achieve International Action on Falsified and Substandard Medicines". British Medical Journal 345 (2012): e7381.

41. IFPMA, The Treat of False Friends: Joining Efforts to Protect Patients Against Online Sales of Fake Medicines (2012). 
42. Newton P., et al. "Manslaughter by Fake Artesunate in Asia: Will Africa Be Next?". PLoS Medicine 3.6 (2006): e197.

43. World Health Organization (WHO) Counterfeits FAQ. World Health Organization (2009).

44. Saez C. "New EU Customs Regulation Might Allow Wrongful Seizures of Generic Drugs in Transit, NGOs Say". Intellectual Property Watch (2013).

45. Kahn U., et al. "Falsified Medicines and the Global Public's Health". Report of Matrix Insight and UCL School of Pharmacy (2012).

46. Buckley GJ and Gostin LO. "Countering the Problem of Falsified and Substandard Drugs". The National Academies Press, Washington, DC. (2013).

47. Smith L and Yadav P. 'Improving Access to Medicines for Non-Communicable Diseases through Better Supply Chains', in: Galambos L and Sturchio J (eds), Addressing the Gaps in Global Policy and Research for Non-Communicable Diseases (2011): 9-12.

48. Mehrotra S and Jarrett S. "Improving Basic Health Service Delivery in Low-Income Countries: "Voice" to the Poor". Social Science and Medicine 54.11 (2002): 1685-1690.

49. World Health Organization (WHO), "Task Shifting: Rational Redistribution of Tasks Among Health Workforce Teams. Geneva: World Health Organization (2008).

50. United Nations Conference on Trade and Development Report titled "The role of competition in the pharmaceutical sector and its benefits for consumers". (2015): 3-15

51. Y Doua., et al. "Registering medicines for low-income countries: how suitable are the stringent review procedures of the World Health Organisation, the US Food and Drug Administration and the European Medicines Agency?". Tropical Medicine and International Health 19.1 (2014): 23-36.

Volume 3 Issue 7 July 2019

(C) All rights are reserved by Pamela Steele., et al. 